\title{
Study on the Strategy of Library Reading Promotion in Big Data Era
}

\author{
Chen Biaobiao,Wang Xiaoping* \\ Hubei Engineering Vocation College, Huangshi City, Hubei Province 435000 \\ 2304360050@qq.com \\ *Corresponding author
}

Keywords: big data, library, reading promotion, personalized service

\begin{abstract}
In the era of big data, readers' reading habits have greatly changed. Readers put forward higher requirements for library services, so it is necessary to explore the opportunity and inspiration brought by big data to libraries. Aiming at the characteristics of readers' reading needs, with the combination of the core value of big data, the strategy of library reading promotion is explored by literature survey method, comparative analysis method, and interdisciplinary approach. Libraries should mine data and establish analysis model to realize the optimal allocation of resources; the information publishing platform should be built to introduce big data and all media into reading promotion, so as to provide personalized service and active push service; readers should be provided with guidance for deep reading; we should track and evaluate the effectiveness of promotion, evaluate the quality of reading service and reading promotion, and constantly conduct the adjustment and amendment.
\end{abstract}

McKinsey, a world-renowned consulting firm is the earliest to put forward that the era of big data has come. It is pointed out in the research report that data have penetrated into every industry and business function field, thus gradually becoming an important factor of production. We have entered an era of mass data storage, mining, analysis and processing to promote social innovation and big data is permeating into every aspect of people's life, work and study with unobstructed majestic momentum, while it also embodies inestimable value of information. From the ten classic cases of successful marketing by using big data, we have sensed the shock power of big data. Library reading promotion recommends and publicizes its services and resources to readers, which is also a non-profit marketing. Libraries should actively explore the opportunity and inspiration brought by big data and big data thinking to guide more readers to read and provide services with higher quality for readers.

\section{Impact of big data on library}

At present, the application of big data is mostly concentrated in enterprises, but it has penetrated into various fields and has a profound impact on the service of the library, which is manifested in the following aspects:

(1) The large data technology has optimized the digital information environment, realized the 
diversified development of the literature resources, and given rise to the new form of literature dissemination and the form of reading media. The service of the stereoscopic communication mode composed of Internet, wireless WiFi, satellite communication is more timely and convenient.[1]

(2) Readers' needs have changed. In the era of big data, people will be placed in a sea of data, while libraries are only a node in a crisscross data network and are no longer the only way for readers to find information resources. Readers are no longer satisfied with the whole book and entire document provided by libraries, but need libraries to solve the specific problems for them, while the unstructured data, thematic knowledge products, and the resources of various carriers other than words are more popular among readers. The data on the relationship between users, users and groups, scientific research groups are the information services required by readers in the era of big data. [2]

(3) With the change in the ways of reading, readers are more and more fond of reading with tools, such as iPad and mobilephone, which can be carried with readers, so that they can use fragmentation time to read at anytime and anywhere with the prevailing of "shallow reading", "fast-food reading" and "fragmentation reading", and readers prefer to communicate in reading, emphasizing the participation and interaction of reading, while publishing comments and sharing pictures or videos through Wechat, micro-blog and other platforms are more popular among readers.

(4) Higher requirements for Libraries' ability to process data are put forward. The scale of data is expanding, and the research of IBM has claimed that $90 \%$ of all data obtained by the whole human civilization is generated in the past two years. It is estimated that by 2020, the scale of the data generated by the world will be 44 times as much as today. There are various types of data, such as web log, picture, audio, video, geolocation information and so on. In the era of big data, in addition to the structured data, there still are interactive information produced by social network, such as users' browsing history, micro-blog, WeChat and mobile library, and libraries need to combine these structured data with these unstructured data for analysis, thus the optimal allocation of resources can be realized.

(5) The purpose of organizing information has changed. The traditional libraries use metadata to describe the characteristics of resources and conduct analysis and mining, with the purpose of resources ordering. In the era of big data, the first is to analyze the data of resources and mine more valuable information, thus providing support for decision or predicting the development of events; the second is to analyze and mine the information of readers to establish effective and accurate analysis model, thus obtaining "truth" from "full data mining", so as to provide the personalized and accurate knowledge service for readers.

(6) The content and mode of information services have changed. The traditional libraries provide readers with complete literature resources, while the era of data provide readers with one-stop service and complete data or information to solve specific problems. The traditional libraries need readers to find resources, while libraries in the era of data actively push resources to readers.

\section{Strategy of library reading promotion in the era of big data}

In 2005, "Nationwide reading” as an important task has been written to "the articles of association of China Society for Library Science” by China Society for Library Science, who has solemnly promised that library takes the promotion of nationwide reading and the supply of guarantee for citizens' lifelong learning as its professional goal and social responsibility.[3] Library community has taken reading promotion and promotion of nationwide reading as their own responsibilities, and various forms of promotion activities have been carried out by libraries, including resource promotion (paper books, databases), service publicity, knowledge promotion (special lectures, knowledge questions and answers), traditional culture promotion (studies of Chinese ancient civilization) and so on, but these activities are mainly based on the promotion of resources, which 
cannot provide personalized services for readers, thus being unable to meet the needs of contemporary readers. The core value of big data is to excavate and analyze users' behavior habits and preferences on the basis of miscellaneous data, so as to find the products and services in line with the "taste" of users, and adjust and optimize themselves according to the needs of users, [4] while the library reading promotion is to provide satisfactory service to more readers by meeting the individualized needs of readers, so as to promote more readers to read, and there is an inherent compatibility between big data and library reading promotion. In the era of big data, libraries should mine data and establish analysis model to realize the optimal allocation of resources; the information publishing platform should be built to introduce big data and all media into reading promotion, thus trying to establish a three-dimensional, omnidirectional, personalized and interactive mode of all media promotion, [5] and various methods and ways should be used to recommend resources to readers; the evaluation system should also be established to evaluate the quality of reading service and reading promotion, and constantly conduct adjustment and amendment.

\subsection{Establishment of big data warehouse of library and analysis model}

According to the data structure, data can be divided into the following types: structured data, unstructured data, and semi structured data between structured and unstructured. The library management system stores the structured data, such as the registered readers' personal identity data, personal borrowing data, borrowing and returning data of library collections, appointment data of library collections, the unstructured data, such as the statistics of time and number of readers entering the library through the entrance guard system, [6] and the metadata that reflect the content and physical characteristics of books. In the traditional library management mode, these data are stored as basic information and statistical information, and management system is just a data warehouse, rather than what we call big data warehouse.

The big data warehouse built by libraries should be like this: It is the general hub of library data, including the decision-making model and evaluation system of library knowledge service and business construction, user behavior value mining, user information data center, reader credit system model, information publishing platform and so on. [7] On the one hand, libraries use big data warehouse to optimize collection structure, mine internal collection statistics data, and establish contact with other libraries, publishing houses, booksellers, e-commerce sales of books, and digital library developers, in order to analyze the data of book author, publishers, hot issues of research in the field of discipline with high utilization and popularity, and reasonably purchase resources; on the other hand, excavate and analyze readers' basic information, reading habits, scientific research trends, establish individual database for each reader, [8] and excavate and analyze users' behavior habits and preferences on the basis of miscellaneous data, so as to find the products and services in line with the "taste" of users, adjust and optimize themselves according to the needs of users, and make use of data information to publish platform publicity and push resources.

\subsection{Strengthening the construction of digital library, mobile library and mobile phone library}

The feature of large data is the mining of massive data. Facing the massive information, readers hope to conduct one-stop retrieval to obtain the information they need as much as possible, and through links and recommendations, the various forms of information about the related subject, such as words, picture, audio, video and so on can be browsed and read at anytime and anywhere. Victor Maier Schoen Berg has pointed out in "the big data era: the great changes in life, work and thinking" that the biggest change in the big data era is to give up the craving of causality and instead focus on the correlation. [9] Big data focuses on relevant relation, and realizes the correlations of related data by relying on the distributed processing, distributed database, cloud storage and / or 
virtualization technology of cloud computing. More and more digital libraries, mobile libraries and mobile phone libraries rely on big data to build relevant knowledge networks, for example, the "knowledge network" built by CNKI includes citation network, related authors, similar literature, readers' recommendation, related fund literature and so on, and it can also build personal library and institutional repository. These databases can achieve one-stop retrieval, and readers can quickly retrieve all kinds of resources of the related topics. In the past, the electronic resources purchased by the library, such as CNKI, Wan Fang and Chao Xing, all restrict readers to read within the IP range, while nowadays, just like Chao Xing, it has launched the account password login mode, by which, the reader can use mobile phone, iPad and other handheld mobile terminal devices to read the electronic resources inside and outside the campus and not be restricted by the time and place of reading. These digital resources including various kinds of books, excellent courses, excellent lectures and so on, has collected entertainment resources and learning resources together and has been processed, with high content and various forms, which can meet the needs of readers.

\subsection{Establishment of digital community for library reading and communication}

Big data is a large group of data in multielement form that are collected from multiple sources, which may be derived from social networks, e-commerce sites, customer visiting records, and many other sources. There is such a statement: Social network allows us more and more to observe the complex behavior patterns of human society from the data, and provides first-hand information for data collection and analysis. Libraries can mine these numerous and jumbled data, analyze users' habits and preferences, and make use of social networking platform to promote resources. The significant feature of big data is to pay attention to the relevance,so it is necessary for the library to learn from the social network communication platform and to establish the digital community of reading promotion and communication, such as the social network platform such as the Douban network, WeChat, micro-blog, Renren network, or to establish their own digital communities for reading and communication by learning from these plaforms, which can realize the following functions: (1) The library can use the social network as the propaganda position of resources and services, so as to make use of the powerful community-based communication function to propagate the promotion activities of the library, and make use of the cross-platform reading sharing and communication to promote the excellent resources to the wider cyberspace. (2) Through the communication and comment functions of digital community, reader's subjective initiative is brought into play, for example, through the WeChat circle, readers can recommend good books to other readers and exchange their reading experience to meet the requirements of readers' reading interactivity in the digital era. (3) These platforms can be used for statistical analysis of readers' behavior, providing data support for establishing the quality index system of reading service and reading promotion. [10] Many domestic libraries have carried out some related attempts, such as the Nanjing University BOOK+, who has interconnected with the Douban to realize the book recommendation function through the book information and book review information provided by the Douban Reading, [11] Tsinghua University, who has set up a library club in Renren networkTsinghua University library book club, [12] the "invincible bookworm" blog in the library of Beijing University of Technology, and the "good book sharing" blog in the library of Hainan University, and so on.

\subsection{Actively push by using big data to study readers’ personalized needs}

The significance of big data is not to grasp huge data, but to process data, mining user behavior data to obtain useful information. The Taobao network and other e-commerce sites, through the analysis of registered users' records of consumption behavior, order information, and so on, analyze 
the users' preferences, and automatically push the commodity information or information that may be interested for users, thus saving the time for the user to find information. [13] Amazon uses users' purchase and browsing historical data to make targeted recommendations of book purchase, so as to effectively enhance the quantity of sale, and the ultimate expectation of Amazon is: "the most successful book recommendation should only have one book, namely, the next book that users want to buy." According to statistics, 30\% of Amazon's sales revenue comes from the "guess you like" recommendation engine. The Shanghai library uses the WeChat public account to launch the "reading bill", where readers can consult the reading records within one year, and analyzes the readers preferences by data mining. [14] Under the background of large data, libraries can mark the readers' characteristics and provide personalized push for readers by collecting a large number of structured and unstructured data, such as readers' borrowing behavior, reading habits, browsing history, searching, consultation and so on; the analysis model of readers' reading experience satisfaction, the analysis model of reader' reading behavior, the influence model of personalized service mode on user churn and other models should be established; through the big data technology, the filtering and integration of cross platform data can be realized, in order to ensure that the information push service can be expanded indefinitely according to the needs of readers. Through the unified identity authentication and unified privilege management for readers, libraries can provide readers with a "one-stop" reading service by making use of web platform, APP client, WeChat public account, social network forum, micro-blog, electronic mailbox and so on, in order to ensure that readers’ personalized reading service has strong mobility and immediacy. [15]

\subsection{Provide readers with reading guidance to guide deep reading}

"Shallow reading" as the typical characteristics of reading in the era of big data means that reading does not need thinking but takes the leaping reading method, which advocates reading pictures, quick reading, shrinking reading, fashion reading and light reading, showing a utilitarian tendency, thus leading to bad consequences such as shallow thinking, insensitive language ability, and gradual loss of cultural background, [1 6] while library should guide and encourage readers with deep reading. The first is to develop mobile reading service to meet the needs of reading with fragmentation time for readers in the era of big data; the second is bibliographic guidance. The library can use big data to analyze the sales of books in Dangdang, Amazon, Douban, publishing house, and bookseller, thus forming the bibliography of best-selling books and classics to recommend to readers, providing the link to the website address to purchase books, the content download of masterpiece and so on, and compiling different bibliographies for different readers; [17] the third is to carry out the micro book review. We find that when choosing a book, readers are accustomed to check the public comments of books on the ecommerce sites such as the Douban and Amazon, while his library can establish its own micro book review column to help readers to find their own reading resources with limited time. Firstly, the librarians are the main force to write the micro book review, and then readers are encouraged to write the micro book review. Only through deep reading can the readers point out the essence and the brilliantly of a book in short and intensive language, arousing the attention of numerous readers, with countless online comments, so as to stimulate more readers to read and discuss with each other, thus forming a virtuous cycle of "participation, understanding, reading and sharing” to arouse readers' enthusiasm for deep reading. Libraries can arrange special staff to select, collect and organize the micro book reviews, which are aggregated into "business cards" of each book through the integration of big data, and they can also follow Sina micro-blog, NetEase micro-blog to establish special subject on micro book review and the community for micro book review, [18] so as to improve readers' enthusiasm for book reading, recommendation and review. 


\subsection{Effectiveness of tracking and evaluating promotion service}

Due to the various forms and simple evaluation, the traditional reading promotion activities are shown with the profit driven and short-term effects, causing that the successful reading promotion activities often stagnates after the upsurge. In the era of big data, library reading promotion should establish a long-term mechanism, promotion should become the routine work of the library, the "activities" should be changed into "service", and the tracking and evaluation system of promotion service should be established to evaluate the practical effect of promotion service through the combination of quantitative and qualitative methods. The library can track and analyze the number and frequency of all the literature used by the readers, and the activities of readers in communication platform and the book review system, as well as the increase in readers' frequency of borrowing, so as to establish "reading bill” for every reader. The analysis of readers' "growth trajectory" in reading can not only evaluate the effectiveness of reading promotion services, but also revise the promotion service to improve the accuracy of service.

\section{Conclusion}

The core value of big data has an inherent compatibility with library reading promotion, which both analyze the user behavior on the basis of numerous and jumbled data, and provide the products and services that conform to the "taste" of users. The library should actively explore the opportunity and inspiration brought by big data and big data thinking to the library, integrate resources, analyze readers' reading behavior, and make use of various media to provide readers with personalized service and active push service, and guide readers for deep reading. However, in order to carry out these services, we need to use the data mining technology, web search technology, knowledge computing and search technology, big data storage and processing technology, cloud computing and so on, which a huge challenge for libraries with relatively weak information technology. In addition, the protection of readers' privacy and information security is also a major problem faced by the library in the era of big data. How to effectively protect the sensitive data and personal privacy of readers' reading activities to prevent from interception, theft, tampering and destruction, has become a key issue to ensure the security of big data environment of the library and the personal reading privacy.

\section{Acknowledgements}

Fund Project: Huangshi Federation of Humanities and Social Sciences "Library Reading Promotion Practice and Exploration in Huangshi District” Project

\section{References}

[1] Liu Lijie,Fan Fengxia. Strategies for Reading Promotion in University Libraries under the Big Data Environment and its Realization Path [J]. Journal of Southwest University (Edition of Humanities and Social Sciences), 2017(8):225 [2] An Zongyu. Analysis of the Impact of Big Data on Libraries and Countermeasures [J]. The Library Journal of Henan, 2014(1):109

[3] China Society for Library Science. The Constitution of China SocietyforLibraryScience[EB/OL].[2017-10-2].http://www.lsc.org.cn/contents/1143/7141.html
[4] Zhang Jianguo. What is the core value of big data? [EB/OL].[2017-9-10].https://www.zhihu.com/question/23273263/answer/221151935

[5] Sun Yuyan. Discussion on the Whole-media Reading Promotion Mode of University Libraries in the Era of Big Data [J]. Journal of Library and Information Sciences in Agriculture, 2017(1):80

[6] Lyu Shanglan. Enlightenment of Big Data Thinking to University Library Reading Promotion [J].Journal of Library Science, 2015(11):79 
[7] Gusu Evening News. The park has created a "10-minute reading circle" [EB/OL].[2017-9-10]. http://suzhou.leju.com/news/2017-09-2/09006317522941118834745.shtml

[8] Xia Ye. Creative Thinking on Library Reading Promotion Under the Perspective of Big Data [J]. Innovation of Science \& Technology, 2017(3):89

[9] Viktor Mayr-Schönberger, Kenneth Cooke. Big Data Era: The Great Transformation of Life, Work, and Thinking [M]. Hangzhou: Zhejiang People's Publishing House, 2013

[10] Wang Xiaoping. Problems and Countermeasures in Library Reading Promotion in the Digital Age [J]. Library World, 2017(2):89

[11] Zhang Yun. Library Socialized Reading Promotion Based on "Douban Reading" Mode [J]. Shanxi Library Journal, 2014(5):4

[12] Tsinghua University Library. Tsinghua University Library Book Club [EB/OL].[2017-10-15].http://page.renren.corn/6000027317checked=true

[13] Bai Hailong. On the Present Situation of Public Library Reading Recommendation Service in the Era of Big Data [J]. Shanxi Library Journal, 2014(4):52

[14] Hu Xinying, Tao Lei. Reading Promotion from the Perspective of Big Data-Taking Shanghai Library as an Example [J]. Information Research, 2017(8): 112-113

[15] Li Hejuan, Hui Qing. Library Reading Promotion Service Strategy in the Background of Big Data [J]. Science \& Technology Vision, 2015(2):39

[16] Li Jin. On the Deep Guidance of Mass Reading in the Light Reading Age [J]. Researches in Library Science, 2008(4):80

[17] Sun Changhong. Respond to the Readers' "Shallow Reading" Libraries Need "Deep Service"[J]. Library Theory and Practice, 2010(6):16

[18] Jin Yanhua. Analysis on the Application Prospect and Implementation Strategy of Microbook Review in Library [J]. Library Work and Study, 2014(4):33-34 